\title{
Impact of acute total occlusion of the culprit artery on outcome in NSTEMI based on the results of a large national registry
}

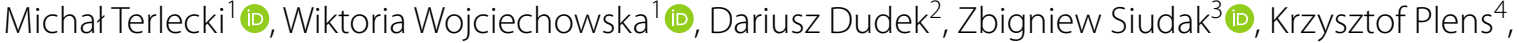

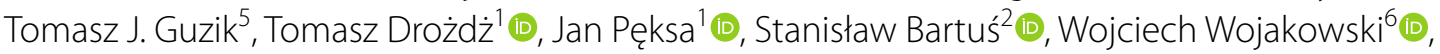 \\ Marek Grygier ${ }^{7}$ (i) and Marek Rajzer ${ }^{1 *}$ (i)
}

\begin{abstract}
Background: The impact of acute total occlusion (TO) of the culprit artery in non-ST-segment elevation myocardial infarction (NSTEMI) is not fully established. We aimed to evaluate the clinical and angiographic phenotype and out-

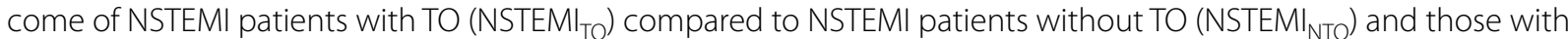
ST-segment elevation and TO (STEMI $\mathrm{TO}_{\mathrm{O}}$ ).

Methods: Demographic, clinical and procedure-related data of patients with acute myocardial infarction who underwent percutaneous coronary intervention (PCI) between 2014 and 2017 from the Polish National Registry were analysed.

Results: We evaluated 131,729 patients: NSTEMI NTO $(n=65,206)$, NSTEMI $(n=16,209)$ and STEMI TO $(n=50,314)$.

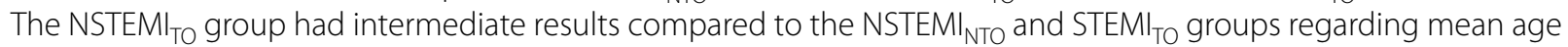
$(68.78 \pm 11.39$ vs $65.98 \pm 11.61$ vs $64.86 \pm 12.04$ (years), $p<0.0001$ ), Killip class IV on admission (1.69 vs 2.48 vs 5.03 (\%), $p<0.0001)$, cardiac arrest before admission (2.19 vs 3.09 vs 6.02 (\%), $p<0.0001$ ) and death during $P C I$ ( 0.43 vs 0.97 vs $1.76(\%), p<0.0001$ )_for NSTEMI $\mathrm{NTO}_{\text {, NSTEMI }}$ and STEMI TO $_{\text {, }}$ respectively. However, we noticed that the NSTEMI group had the longest time from pain to first medical contact (median 4.0 vs 5.0 vs 2.0 (hours), $p<0.0001$ ) and the lowest frequency of TIMI flow grade 3 after PCI (88.61 vs 83.36 vs $95.57(\%), p<0.0001)$ and that the left circumflex artery (LCX) was most often the culprit lesion (14.09 vs 35.86 vs $25.42(\%), p<0.0001$ ).
\end{abstract}

Conclusions: The NSTEMI ${ }_{\text {TO }}$ group clearly differed from the NSTEMI ${ }_{\text {NTO }}$ group. NSTEMI $I_{\text {TO }}$ appears to be an intermediate condition between NSTEMI $\mathrm{NTO}_{\mathrm{O}}$ and STEMI $\mathrm{TO}_{\mathrm{O}}$ although NSTEMI $\mathrm{TO}_{\mathrm{O}}$ patients have the longest time delay to and the worst result of $\mathrm{PCl}$, which can be explained by the location of the culprit lesion in the $\mathrm{LCX}$.

Keywords: Myocardial infarction, STEMI, NSTEMI, Coronary angiography, Total artery occlusion

*Correspondence: rajzer37@interia.pl

1 Jagiellonian University Medical College, 1st Department of Cardiology, Interventional Electrocardiology and Arterial Hypertension,

Jakubowskiego St. 2, 30-688 Kraków, Poland

Full list of author information is available at the end of the article

\section{Background}

According to the European Society of Cardiology (ESC) guidelines, patients with myocardial infarction (MI) and ST-segment elevation (STEMI) are eligible for emergency reperfusion therapy, whereas those with non-ST-segment elevation MI (NSTEMI) require further risk stratification; thus, the qualification for invasive diagnosis and treatment is delayed [1]. The STEMI-NSTEMI paradigm 
is based on the observation that ST-segment elevation (STE) on the electrocardiogram (ECG) in the majority of patients with $\mathrm{MI}$ is associated with acute total occlusion (TO) of the infarct-related artery (IRA), while subtotal IRA occlusion leads mostly to ST-segment depression and negative T-waves on the ECG. However, when qualification for emergency reperfusion therapy is based on ECG criteria, we lose approximately $25 \%$ of patients with acute TO of the IRA who do not present STE [2]. NSTEMI patients form a very heterogeneous group, and ESC guidelines recommend urgent coronary angiography only for those with life-threatening ventricular arrhythmias, resistant angina pectoris and haemodynamic instability. These conditions may be accompanied by total IRA occlusion, but this is not always the case. Thus, percutaneous coronary intervention (PCI) may be deferred in a substantial subset of NSTEMI patients with TO of the IRA, which may result in delayed myocardial salvage and poor cardiovascular outcomes [3].

This study aimed to identify the key points of clinical characteristics, course of treatment and outcome of patients with NSTEMI with TO of the IRA (NSTEMI ${ }_{\mathrm{TO}}$ ) by comparison with the two most outlying groups: patients with NSTEMI and a non-occluded coronary artery $\left(\mathrm{NSTEMI}_{\mathrm{NTO}}\right)$ and patients with STE and an occluded IRA (STEMI $\mathrm{TO}_{\mathrm{TO}}$ ).

\section{Methods}

We analysed the data of patients with MI assembled within 48 months (2014-2017) into the Polish National Database of Invasive Coronary Procedures (ORPKI), coordinated by Jagiellonian University Medical College and endorsed by the Association of Cardiovascular Interventions of the Polish Cardiac Society [4]. All clinical data were collected by the operator and then uploaded into the database after each procedure. The diagnosis of NSTEMI or STEMI, recognition of the IRA, all clinical decisions during the coronary invasive procedure and definitions of periprocedural complications were left to the uploading ORPKI operators' experience and knowledge according to current ESC guidelines.

Acute TO of the IRA was defined in our study as Thrombolysis In Myocardial Infarction (TIMI) 0 flow during coronary angiography in patients with MI [5].

To achieve the aim of the study, we compared 3 groups of patients: $\mathrm{NSTEMI}_{\mathrm{TO}}$, $\mathrm{NSTEMI}_{\mathrm{NTO}}$ and $\mathrm{STEMI}_{\mathrm{TO}}$ and excluded from the analysis patients with STEMI and non-occluded coronary artery $\left(\mathrm{STEMI}_{\mathrm{NTO}}\right)$, those without significant coronary artery stenosis, those not treated with PCI and those diagnosed with chronic total occlusion of the IRA. To minimize confounding factors influencing the electrocardiographic presentation of $\mathrm{MI}$, we decided to perform angiographic analysis only for patients with PCI of single native vessel disease.

Our study was an observational, non-experimental, retrospective analysis and was performed in accordance with the relevant guidelines and regulations. Only anonymized data were included in the research analysis, and according to Regulation 2016/679 of the European Parliament and of the Council (EU) from 27 April 2016 on the protection of individuals with regard to the processing of personal data and on the free movement of such data and with art. 9 section 2, this study did not require any additional ethics board approval. All subjects in our study gave informed consent for personal data processing by the Association of Cardiovascular Interventions of the Polish Cardiac Society before percutaneous coronary intervention.

\section{Statistical analysis}

Categorical variables are presented as numbers and percentages. Continuous variables are expressed as the mean \pm standard deviation (SD) or the median and interquartile range (IQR). The normality of continuous variables was assessed by the Kolmogorov-Smirnov-Lilliefors test. Equality of variance was assessed using Levene's test. Differences between three groups were compared using classic one-way analysis of variance (ANOVA) or Welch's ANOVA depending on the equality of variance for normally distributed variables. The Kruskal-Wallis test was used for ordinal or non-normally distributed continuous variables. Categorical variables were compared by Pearson's chi-square test. All post hoc analyses were performed using the Benjamini-Hochberg procedure for controlling the false discovery rate (FDR). Two-sided p-values $<0.05$ were considered statistically significant. All calculations were performed with $\mathrm{JMP}^{\circledR}$, Version 14.2.0 (SAS Institute Inc., Cary, NC, USA).

\section{Results}

The results of 245,869 coronary angiography procedures performed in patients with MI were entered into the ORPKI registry. After exclusion of patients (a) without significant stenosis of coronary arteries, (b) without occlusion of the IRA in STEMI, (c) without PCI treatment; (d) with chronic total occlusion of the IRA and (e) with multivessel PCI treatment, 131,729 patients who underwent single-vessel PCI constituted the study group. Among them, 65,206 (80.09\%) patients with NSTEMI had no TO of the IRA (TIMI >0), while total occlusion of the IRA (TIMI =0) was found in 16,209 $(19.91 \%)$ patients with NSTEMI and 50,314 (48.21\%) with STEMI. The study flowchart is shown in Fig. 1. 


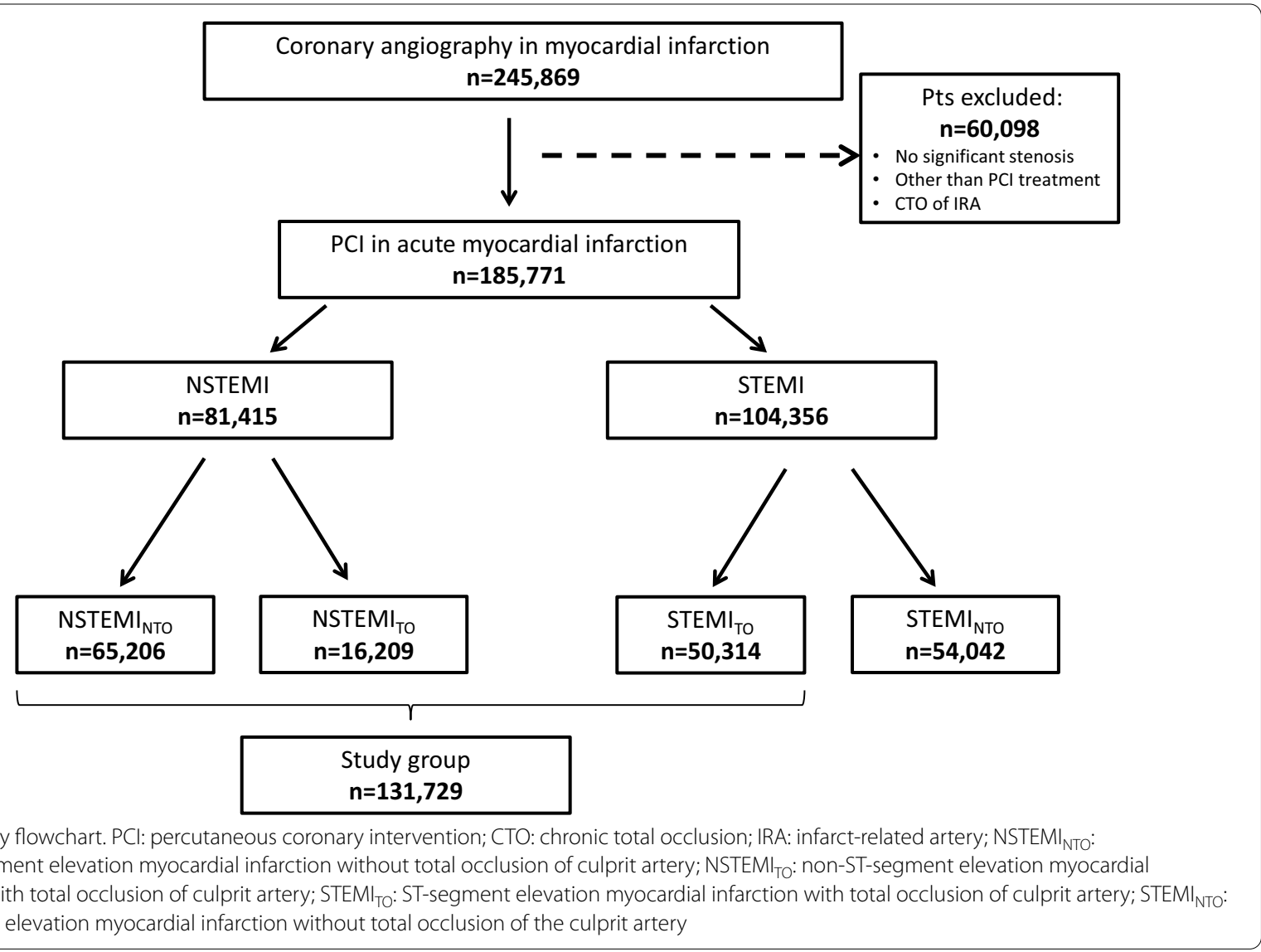

\section{Clinical characteristics of the study groups}

Patients with NSTEMI $\mathrm{TO}_{\mathrm{TO}}$ were younger than those with $\mathrm{NSTEMI}_{\mathrm{NTO}}$ but older than patients with STEMI $\mathrm{TO}_{\mathrm{TO}}$ The percentage of smokers was highest in the STEMI group, lower in the $\mathrm{NSTEMI}_{\mathrm{TO}}$ group and lowest in NSTEMI $_{\text {NTO group. The prevalence of chronic diseases }}$ (arterial hypertension, diabetes, chronic kidney disease, chronic obstructive pulmonary disease) was highest in the $\mathrm{NSTEMI}_{\mathrm{NTO}}$ group, lower in the $\mathrm{NSTEMI}_{\mathrm{TO}}$ group and lowest in the STEMI $\mathrm{TO}_{\mathrm{TO}}$ group. All of the aforementioned differences were significant $(\mathrm{p}<0.0001)$. A similar tendency was observed in the history of previous coronary revascularization (PCI or CABG), MI or stroke, which were most common in patients with $\mathrm{NSTEMI}_{\mathrm{NTO}}$, less common in those with NSTEMI $\mathrm{TO}_{\mathrm{TO}}$ and least common in those with STEMI $_{\mathrm{TO}}(\mathrm{p}<0.0001)$.

Clinical status on admission in the $\mathrm{NSTEMI}_{\mathrm{TO}}$ group was more severe than that in the NSTEMI $_{\mathrm{NTO}}$ group but less serious than that in the $\mathrm{STEMI}_{\mathrm{TO}}$ group. More advanced Killip classes were observed with the highest frequencies in patients with $\mathrm{STEMI}_{\mathrm{TO}}$, lower frequencies in those with $\mathrm{NSTEMI}_{\mathrm{TO}}$ and the lowest frequen-

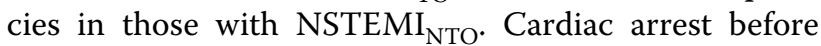
admission was more common in patients with $\mathrm{STEMI}_{\mathrm{TO}}$ than in those with $\mathrm{NSTEMI}_{\mathrm{TO}}$ and more common in patients with NSTEMI ${ }_{\mathrm{TO}}$ than in those with NSTEMI $_{\mathrm{NTO}}$ (Table 1).

\section{Time delays in MI treatment within study groups}

Direct transport to the catherization laboratory (Cath lab) was most common in the STEMI $\mathrm{TO}_{\mathrm{TO}}$ group, less common in the NSTEMI ${ }_{\mathrm{TO}}$ group and least common in the $\mathrm{NSTEMI}_{\mathrm{NTO}}$ group. The time from pain to first medical contact (FMC) was longer in the NSTEMI $\mathrm{TO}_{\mathrm{TO}}$ group than in either the $\mathrm{STEMI}_{\mathrm{TO}}$ or $\mathrm{NSTEMI}_{\mathrm{NTO}}$ group. Time periods (from pain to balloon inflation and from FMC to inflation) were shortest in the $\mathrm{STEMI}_{\mathrm{TO}}$ group, intermediate in the $\mathrm{NSTEMI}_{\mathrm{TO}}$ group and longest in the NSTEMI $_{\text {NTO }}$ group. Time from FMC to inflation $<90 \mathrm{~min}$ and time from FMC to inflation $<120$ min were observed most frequently in patients with $\mathrm{STEMI}_{\mathrm{TO}}$, less frequently in those with NSTEMI $\mathrm{TO}_{\mathrm{TO}}$ and least frequently in

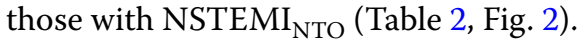

\section{Results of coronary angiography}

In our study, the left anterior descending artery (LAD) was identified as the IRA in 45,008 patients; the left circumflex artery (LCx), in 29,479 patients; and the right 
Table 1 Clinical characteristics of the study groups

\begin{tabular}{|c|c|c|c|}
\hline & NSTEMI $_{\text {NTO }}(\mathrm{N}=65,206)$ & NSTEMI $_{\mathrm{TO}}(\mathrm{N}=16,209)$ & STEMI $_{\text {TO }}(\mathrm{N}=50,314)$ \\
\hline Age (years), mean (SD) & $68.78(11.39)$ & $65.98(11.61)$ & $64.86(12.04)$ \\
\hline Male sex ${ }^{\mathrm{a}}, \mathrm{n}(\%)$ & $42.380(65.19 \%)$ & $11.215(69.53 \%)^{*}$ & $34.133(68.00 \%)$ \\
\hline Weight (kg), mean (SD) & $79.98(17.49)$ & $81.64(17.54)$ & $80.52(16.67)$ \\
\hline Smokers, n (\%) & $14.075(21.59 \%)$ & $4.303(26.55 \%)$ & $14.842(29.50 \%)$ \\
\hline Arterial hypertension, n (\%) & $47.872(73.42 \%)$ & $11.222(69.23 \%)$ & $29.912(59.45 \%)$ \\
\hline Diabetes, n (\%) & $17.774(27.26 \%)$ & $3.737(23.06 \%)$ & $8.729(17.35 \%)$ \\
\hline Kidney disease, n (\%) & $5.633(8.64 \%)$ & $948(5.85 \%)$ & $1.647(3.27 \%)$ \\
\hline $\mathrm{COPD}^{\mathrm{b}}, \mathrm{n}(\%)$ & $1.718(3.61 \%)$ & $343(2.90 \%)^{\$}$ & $659(1.75 \%)$ \\
\hline Previous stroke, n (\%) & $2.877(4.41 \%)$ & $671(4.14 \%)^{\#}$ & $1.687(3.35 \%)$ \\
\hline Previous PCl, n (\%) & $17.433(26.74 \%)$ & $3.027(18.67 \%)$ & $6.010(11.94 \%)$ \\
\hline Previous CABG, n (\%) & $4.300(6.59 \%)$ & $835(5.15 \%)$ & $814(1.62 \%)$ \\
\hline Previous MI, n (\%) & $18.406(28.23 \%)$ & $3.550(21.90 \%)$ & $6.493(12.90 \%)$ \\
\hline Killip class IIc, n (\%) & $1.051(2.25 \%)$ & $325(2.47 \%)$ & $1.431(3.33 \%)$ \\
\hline Killip class IV', n (\%) & $787(1.69 \%)$ & $326(2.48 \%)$ & $2.162(5.03 \%)$ \\
\hline Cardiac arrest before admission ${ }^{d}, \mathrm{n}(\%)$ & $1.208(2.19 \%)$ & 477 (3.09\%) & $2.962(6.02 \%)$ \\
\hline Cardiac arrest during angiography ${ }^{\mathrm{d}}, \mathrm{n}(\%)$ & $151(0.27 \%)$ & $82(0.53 \%)$ & $19(0.04 \%)$ \\
\hline
\end{tabular}

$p<0.0001$ for all analyses of the study groups by Kruskal-Wallis one-way analysis of variance

Data are presented as the mean and standard deviation (SD) or number ( $\mathrm{n}$ ) and percentage (\%)

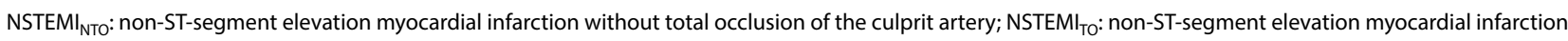
with total occlusion of the culprit artery; STEMI $_{\mathrm{TO}}$ : ST-segment elevation myocardial infarction with total occlusion of the culprit artery; COPD: chronic obstructive pulmonary disease; $\mathrm{PCl}$ : percutaneous coronary intervention; CABG: coronary artery bypass graft; MI: myocardial infarction

$p<0.0001$ for all post hoc analyses with the following exceptions:

${ }^{*} \mathrm{p}=0.0003$ for post hoc comparison between NSTEMI $\mathrm{TO}_{\mathrm{O}}$ and $\mathrm{STEMI} \mathrm{TO}_{\mathrm{T}}$;

${ }^{\$} \mathrm{p}=0.0002$ for post hoc comparison between $\mathrm{NSTEMI}_{\mathrm{NTO}}$ and $\mathrm{NSTEMI}_{\mathrm{TO}}$;

$\# \mathrm{p}=0.1283$ for post hoc comparison between $\mathrm{NSTEMI}_{\mathrm{NTO}}$ and NSTEMI

Data available for ${ }^{a}-131,452$ patients, ${ }^{b}-96,952$ patients, ${ }^{c}-102,807$ patients, ${ }^{d}-119,955$ patients

Table 2 Comparison of patient- and system-related delays to primary PCI

\begin{tabular}{|c|c|c|c|}
\hline & NSTEMI $_{\mathrm{NTO}}(\mathrm{N}=65,206)$ & NSTEMI $_{T O}(\mathrm{~N}=16,209)$ & $\operatorname{STEMI}_{\mathrm{TO}}(\mathrm{N}=50,314)$ \\
\hline Direct transport to Cath laba ${ }^{a}$ n (\%) & $3.682(6.66 \%)$ & $1.412(9.14 \%)$ & $1.2645(25.69 \%)$ \\
\hline \multicolumn{4}{|l|}{ Time from } \\
\hline Pain to $\mathrm{FMC}^{\mathrm{b}}(\mathrm{h})$, median (IQR) & $4.00(2.00-11.00)$ & $5.00(2.00-14.00)$ & $2.00(1.00-5.53)$ \\
\hline Pain to inflation ${ }^{c}(\mathrm{~h})$, median (IQR) & $14.42(7.00-30.98)$ & $12.48(6.38-27.00)$ & $4.00(2.33-8.50)$ \\
\hline FMC to inflation ${ }^{d}(h)$, median (IQR) & $6.00(2.42-17.00)$ & $4.17(2.00-9.67)$ & $1.40(0.97-2.25)$ \\
\hline FMC to inflation ${ }^{d}<90 \mathrm{~min}, \mathrm{n}(\%)$ & $7.008(14.05)$ & $2.618(18.61)$ & $24.268(53.07)$ \\
\hline FMC to inflation ${ }^{d} \leq 120$ min, $n(\%)$ & $9.553(19.16)$ & $3.445(24.48)$ & $31.098(68.01)$ \\
\hline
\end{tabular}

$p<0.0001$ for all analyses of the study groups by Kruskal-Wallis one-way analysis of variance

Data are presented as the median and interquartile range (IQR) or number ( $n$ ) and percentage (\%);

$\mathrm{NSTEMI}_{\mathrm{NTO}}$ : non-ST-segment elevation myocardial infarction without total occlusion of culprit artery; $\mathrm{NSTEMI}_{\mathrm{TO}}$ : non-ST-segment elevation myocardial infarction with total occlusion of culprit artery; $\mathrm{STEMI}_{\mathrm{TO}}$ : ST- segment elevation myocardial infarction with total occlusion of culprit artery; Cath lab: catheterization laboratory;

$\mathrm{p}<0.0001$ for all post hoc analyses;

Data available for ${ }^{\mathrm{a}}-119,955$ patients, ${ }^{\mathrm{b}}-107,435$ patients, $^{\mathrm{c}}-109,566$ patients, ${ }^{\mathrm{d}}-109,664$ patients

coronary artery (RCA), in 36,828 patients. Other culprit localizations (i.e., left main, coronary artery bypass grafts, bifurcations) were found in 10,223 patients, and this subset of patients who did not fulfil the criteria of single native vessel disease PCI was excluded from further analysis (Fig. 3). Among patients with $\mathrm{NSTEMI}_{\mathrm{TO}}$, LCx was the most frequent single native vessel occlusion. In contrast, occlusion of LAD as the culprit lesion was observed the least often in this group. In patients with $\mathrm{STEMI}_{\mathrm{TO}}$, LCx occlusion was infrequent, while occlusion 


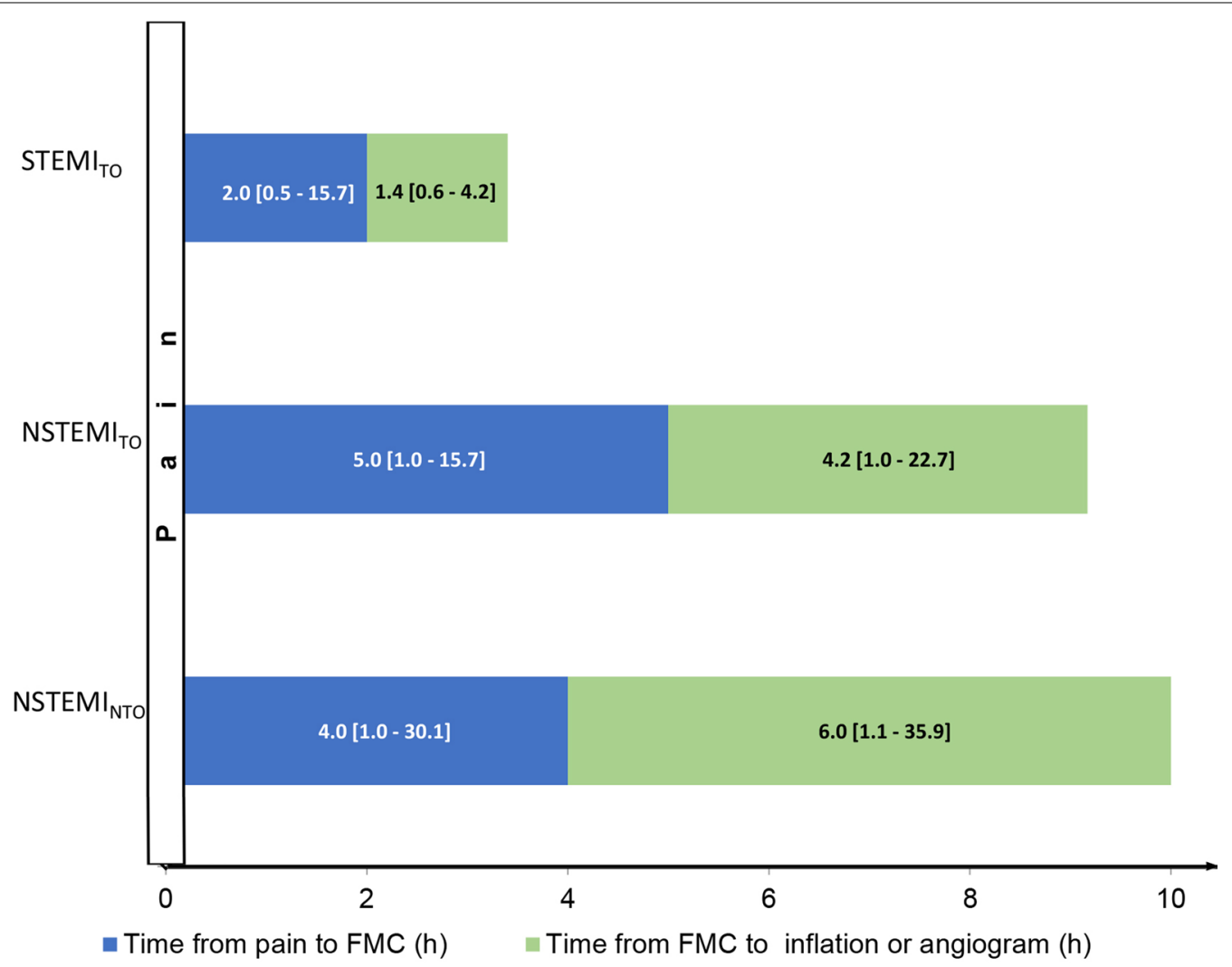

Fig. 2 Comparison of median time from pain to first medical contact (FMC) and from FMC to balloon inflation or angiogram. Data are presented as the median, $p<0.0001$ for all post hoc analyses

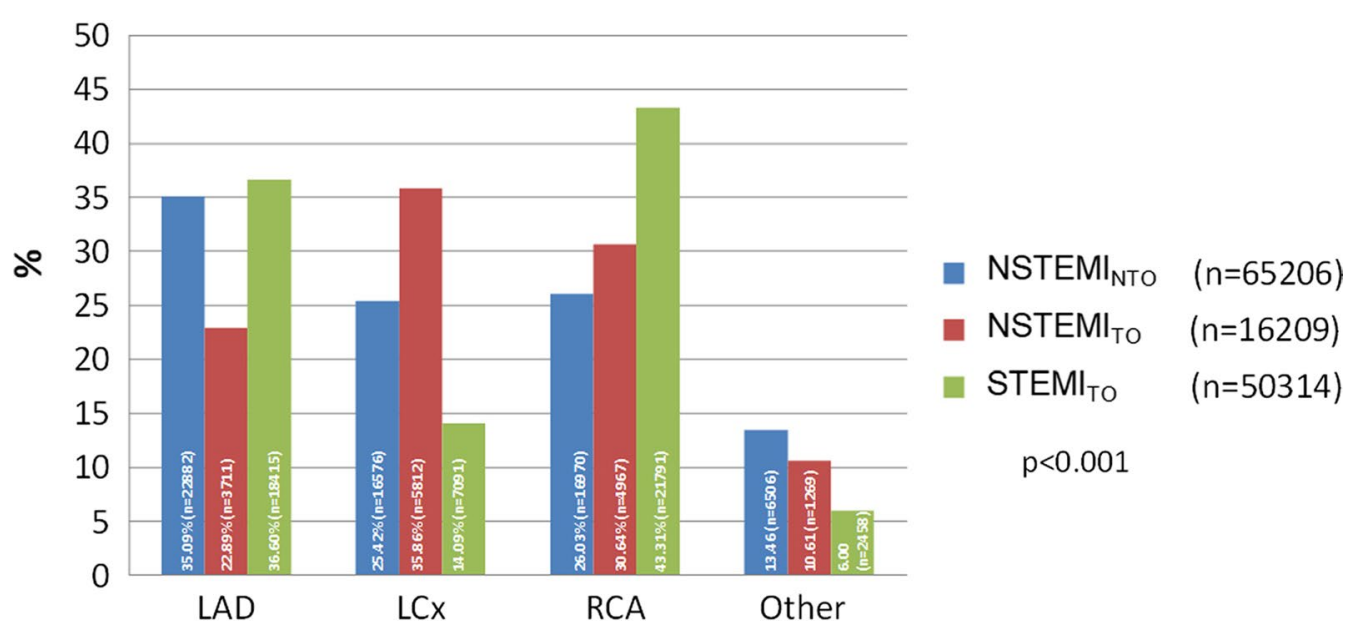

\section{Culprit artery PCI}

Fig. 3 The frequency rate of culprit lesions for the left anterior descending artery $(L A D)$, left circumflex artery ( $L C X)$, right coronary artery (RCA) and other arteries within the study groups. $p<0.0001$ for all analyses of study groups by Kruskal-Wallis one-way analysis of variance, $p<0.0001$ for all post hoc analyses, $p$ for contingency analysis $<0.0001$ 
of the RCA or LAD was prevalent. NSTEMI $\mathrm{NTO}_{\text {NO }}$ related most often to LAD as the culprit lesion, less commonly to RCA and least often to LCx (p for contingency analysis $<0.0001)$.

\section{Analyses of $\mathrm{PCl}$ results}

The successful revascularization outcome defined as TIMI flow grade after PCI in the NSTEMI $\mathrm{TO}_{\mathrm{TO}}$ group was worse than that in the STEMI $\mathrm{TO}_{\mathrm{TO}}$ and NSTEMI $\mathrm{NTO}_{\mathrm{NO}}$ groups (Table 3). TIMI flow grade 3 was reached with the lowest frequency in the IRA after PCI, and TIMI flow grade 0 after PCI was noticed with the highest occurrence rate in the NSTEMI ${ }_{\mathrm{TO}}$ group compared with both the STEMI and NSTEMI $\mathrm{NTO}_{\text {NTO }}$ groups. The no-reflow phenomenon, cardiac arrest during PCI and death during the invasive procedure in the NSTEMI quently than in the STEMI ${ }_{\mathrm{TO}}$ group but more frequently than in the NSTEMI $\mathrm{NTO}_{\text {group. }}$

\section{Discussion}

To the best of our knowledge, we conducted the largest single-study analysis dedicated to the NSTEMI $\mathrm{TO}_{\mathrm{TO}}$ phenomenon (16,209 patients). The previous meta-analyses on this topic included 10,415 patients (7 studies) and 17,212 patients (25 studies) with NSTEMI ${ }_{\mathrm{TO}}[6,7]$.

Our study results suggest that $\mathrm{NSTEMI}_{\mathrm{TO}}$ may be considered an intermediate condition between NSTEMI $_{\text {NTO }}$ and STEMI $\mathrm{TO}_{\mathrm{TO}}$. However, the following features make the NSTEMI $_{\mathrm{TO}}$ group exceptional:

- The longest time delay to obtain proper medical care (patients with NSTEMI STEMI ${ }_{\text {TO }}$ patients had already undergone $\mathrm{PCI}$ ),

- LCx as the most frequent infarct-related artery, and

- The worst final result of PCI.
Numerous studies have shown the differences in the baseline clinical presentation between patients with STEMI and NSTEMI. In the OPERA Registry, correlates of mid- and long-term mortality were similar for NSTEMI and STEMI patients [8]. This leads to the conclusion that we should not consider STEMI and NSTEMI to be two different diseases but rather as an ischaemic continuum due to subtotal or total occlusion of the coronary artery with different ECG manifestations [9, 10]. Total occlusion of the IRA can occur in STEMI and NSTEMI patients. Numerous studies have compared acute total occlusion of the IRA with non-total occlusion of the IRA but mostly within the NSTEMI subset of patients $[11,12]$. Our goal was to compare three manifestations of acute MI: NSTEMI $\mathrm{NTO}_{\mathrm{NO}}, \mathrm{NSTEMI}_{\mathrm{TO}}$ and $\mathrm{STEMI}_{\mathrm{TO}}$; thus, for the first time, we compared three groups instead of two.

Considering the baseline characteristics, patients with $\mathrm{NSTEMI}_{\mathrm{TO}}$ in our study constituted an intermediate group between NSTEMI $\mathrm{NTO}_{\text {and STEMI }}$. In comparison to STEMI $\mathrm{TO}_{\mathrm{TO}}$ patients, NSTEMI $\mathrm{TO}_{\mathrm{TO}}$ patients were older and had a higher prevalence of cardiovascular risk factors and chronic diseases. When comparing NSTEMI NSTEMI $_{\mathrm{NTO}}$, the patients were younger and had a lower prevalence of cardiovascular risk factors and chronic diseases. These findings are in accordance with other studies, where patients with NSTEMI, in comparison to STEMI, were older and more often had chronic diseases $[13,14]$. According to the baseline characteristics, our NSTEMI $_{\mathrm{TO}}$ group was definitely closer to the $\mathrm{STEMI}_{\mathrm{TO}}$ group than to the NSTEMI ${ }_{\mathrm{NTO}}$ group. Patients with STEMI $_{\text {NTO }}$ were excluded due to high group heterogeneity. To summarize the results of pre-hospital management, participants with NSTEMI $\mathrm{TO}_{\mathrm{TO}}$ were generally less frequently considered candidates for direct transportation to the Cath lab than STEMI ${ }_{\mathrm{TO}}$ patients $(9.41 \%$ vs

Table 3 Percutaneous coronary intervention results

\begin{tabular}{|c|c|c|c|}
\hline & NSTEMI $_{\text {NTO }}(\mathrm{N}=65,206)$ & NSTEMI $_{\text {то }}(\mathrm{N}=16,209)$ & $\mathrm{STEMI}_{\mathrm{TO}}(\mathrm{N}=50,314)$ \\
\hline TIMI 3 after $\mathrm{PCI}^{\mathrm{a}}, \mathrm{n}(\%)$ & $62.114(95.57)$ & $13.483(83.36)^{*}$ & $44.494(88.61)$ \\
\hline TIMI 2 after $\mathrm{PCl}^{\mathrm{a}}, \mathrm{n}(\%)$ & $1.678(2.58)$ & $834(5.16)^{*}$ & $2.921(5.82)$ \\
\hline TIMI 1 after $\mathrm{PCI}^{\mathrm{a}}, \mathrm{n}(\%)$ & $531(0.82)$ & $333(2.06)^{*}$ & $971(1.93)$ \\
\hline TIMI 0 after $\mathrm{PCI}^{\mathrm{a}}, \mathrm{n}(\%)$ & $672(1.03)$ & $1.525(9.43)^{*}$ & $829(3.64)$ \\
\hline No reflow after $\mathrm{PCl}, \mathrm{n}(\%)$ & $315(0.48)$ & $218(1.34 \%)^{*}$ & $878(1.75 \%)$ \\
\hline Cardiac arrest during $\mathrm{PCl}, \mathrm{n}(\%)$ & $361(0.55)$ & $175(1.08)^{*}$ & $1.198(2.38 \%)$ \\
\hline Death during $\mathrm{PCl}, \mathrm{n}(\%)$ & $281(0.43)$ & $158(0.97)^{*}$ & $885(1.76 \%)$ \\
\hline
\end{tabular}

$\mathrm{p}<0.0001$ for all analyses of study groups by analysis of variance

NSTEMI $_{\text {NTO: }}$ non-ST-segment elevation myocardial infarction without total occlusion of culprit artery; $\mathrm{NSTEMI}_{\mathrm{TO}}$ : non-ST-segment elevation myocardial infarction with total occlusion of culprit artery; STEMI $_{\mathrm{TO}}$ : ST- segment elevation myocardial infarction with total occlusion of culprit artery; TIMI: Thrombolysis in Myocardial Infarction; $\mathrm{PCl}$ : percutaneous coronary intervention

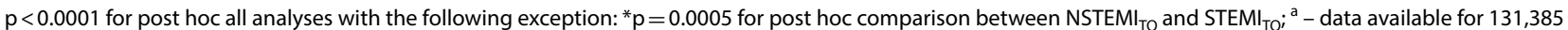
patients 
25.69\%). Additionally, ischaemia time, i.e., time from pain to balloon inflation, as well as time from FMC to balloon inflation, were longer in the $\mathrm{NSTEMI}_{\mathrm{TO}}$ group than in the STEMI ${ }_{\text {TO }}$ group. The duration of ischaemia is a major determinant of infarct size and subsequent mortality [3, 15]. In almost all studies included in the meta-analysis of Khan et al., patients with $\mathrm{NSTEMI}_{\mathrm{TO}}$ had a mean delay to invasive procedure longer than $24 \mathrm{~h}$ and, in comparison to patients with $\mathrm{NSTEMI}_{\mathrm{NTO}}$, an increased risk of both major adverse cardiovascular events and mortality [6]. The mean time from pain to inflation in our study was approximately $30 \mathrm{~h}$ (data not presented) and was similar to that presented by Khan et al. [6].

The time from pain to FMC was the longest in the NSTEMI $_{\text {TO }}$ group and was even longer than that in the $\mathrm{NSTEMI}_{\mathrm{NTO}}$ group. In the NSTEMI $\mathrm{TO}_{\mathrm{TO}}$ group, patients postponed the decision to seek medical help, probably because of younger age (than in the $\mathrm{NSTEMI}_{\mathrm{NTO}}$ group) and a lack of previous experience with stenocardial pain. The longer time delay from pain to FMC in $\mathrm{NSTEMI}_{\mathrm{TO}}$ than in $\mathrm{STEMI}_{\mathrm{TO}}$ may be explained by the lower severity of symptoms due to the lower degree of ischaemia in the case of LCx occlusion.

The time delay to achieve the opening of the occluded

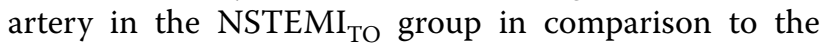
$\mathrm{STEMI}_{\mathrm{TO}}$ group was amplified during in-hospital management, which was noticeable as the pronounced difference (median time from FMC to balloon inflation was almost three times longer in the NSTEMI $\mathrm{TO}_{\text {group). }}$

In contrast, patients with $\mathrm{NSTEMI}_{\mathrm{TO}}$ in comparison to those with NSTEMI NTO $_{\text {were previously considered }}$ candidates for invasive management. The potential explanation is the more severe clinical presentation caused by total artery occlusion. The higher frequency of cardiac arrest before admission and more advanced Killip class in the NSTEMI $\mathrm{TO}_{\mathrm{TO}}$ group than in the $\mathrm{NSTEMI}_{\mathrm{NTO}}$ group in our study confirm this hypothesis. Similar results were obtained by Shin et al. in the COREA-AMI Registry [16]. Another commonly used parameter of time delay in MI that influences prognosis is the percentage of patients who undergo PCI within $120 \mathrm{~min}$ since the onset of symptoms $[3,15,17]$. In the study of Terkelsen et al., approximately $50 \%$ of STEMI patients had balloon inflation within $120 \mathrm{~min}$ [17]. In our study, almost $70 \%$ of STEMI $_{\text {TO }}$ patients, but only $25 \%$ of NSTEMI TO $_{\text {patients, }}$ had PCI within $120 \mathrm{~min}$.

Approximately $20 \%$ of our NSTEMI patients had acute coronary artery occlusion, which is less than that previously reported by Khan (25.5\%) and Hung (34\%) [6, 7]. This difference may be explained by the fact that we used a stricter definition of $\mathrm{NSTEMI}_{\mathrm{TO}}$, analysing only patients with TIMI 0 flow, whereas Khan and Hung included patients with TIMI 0-1. Previous studies examining the distribution of occluded arteries in $\mathrm{NSTEMI}_{\mathrm{TO}}$ patients indicated that the RCA or LCx was the artery most responsible for $\mathrm{NSTEMI}_{\mathrm{TO}}[6,7]$. In our study, we found that the LCx was the most typical localization of the culprit lesion responsible for $\mathrm{MI}$ in the $\mathrm{NSTEMI}_{\mathrm{TO}}$ group. The distribution of the IRA differs between trials when STEMI cases are compared to NSTEMI, i.e., in STEMI, there is underrepresentation of the LCx as the IRA [18], whereas in NSTEMI $\mathrm{TO}_{\mathrm{TO}}$, occlusion of the LAD occurs the least often [7, 19]. We must acknowledge that ECG has unsatisfactory sensitivity for diagnosis of coronary artery total occlusion, especially in posterolateral distribution [20].

In our study, patients with NSTEMI $\mathrm{TO}_{\text {O }}$ demonstrated a more severe clinical condition on admission than those with NSTEMI $_{\text {NTO }}$ (more advanced Killip class, higher prevalence of death and cardiac arrest prior to admission or during an invasive procedure, no-reflow phenomenon), which is in concordance with prior studies showing that the prognosis of patients with total occlusion without ST-segment elevation is worse than that of

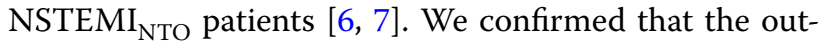
come after PCI (lower frequency of achieving TIMI 3 and higher frequency of TIMI 0) in NSTEMI TO $_{\text {patients }}$ is even inferior to that in $\mathrm{STEMI}_{\mathrm{TO}}$ patients. A possible explanation is that unrecognized acute coronary artery occlusion is associated with high morbidity and mortality [15], and the outcome in this group is worse than that in the group that received timely revascularization $[11,21]$.

In summary, we must acknowledge that the identification of NSTEMI $\mathrm{TO}_{\mathrm{TO}}$ patients prior to coronary angiography remains challenging. Among the NSTEMI patients in our study, younger patients with a lower frequency of comorbidities (which is not a typical NSTEMI group characteristic) should be highly suspected of having acute total occlusion of the infarct-related artery if they present severe symptoms on admission (i.e., advanced Killip class, pre-hospital cardiac arrest, long pain duration), which enables us classify them into the very high-risk group according to the most current 2020 ESC NSTEMI guidelines [22]. To select high-risk patients who require urgent coronary intervention, we should exert additional effort and use all available methods, i.e., careful clinical assessment, ECG analysis including additional ECG leads (i.e., V7-V9) and patterns that are highly suggestive of TO of the IRA (extensively described in the supplementary table of 2020 ESC NSTEMI guidelines), specific risk score calculation and echocardiography examination with wall motion and strain analysis [22].

\section{Study limitations}

Our study has several limitations. First, we should be very cautious about drawing conclusions about detailed 
in-hospital prognoses because our analysis is based on data from the structured registry that included prespecified clinical and a periprocedural data spectrum only, without longitudinal follow-up, but with the largest number of evaluated patients thus far. Second, the registry was created, and data were entered by several operators; the quality of data depends on their individual knowledge. However, only the most experienced operators collected the data.

\section{Conclusions}

Approximately one-fifth of NSTEMI patients had acute total coronary artery occlusion $\left(\mathrm{NSTEMI}_{\mathrm{TO}}\right)$. According to the clinical characteristics, NSTEMI ${ }_{\mathrm{TO}}$ seems to be an intermediate condition between NSTEMI $_{\text {NTO }}$

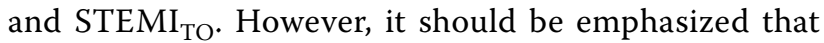
NSTEMI $_{\text {TO }}$ patients have the longest time delay to PCI and the worst final result of PCI, which can be at least partially explained by the most common location of the culprit lesion in the LCx. Therefore, patients with NSTEMI should undergo strict evaluation for signs indicating possible acute total coronary artery occlusion (e.g., younger age, lower cardiovascular risk, fewer chronic diseases but more severe clinical presentation on admission) and should undergo comprehensive ECG and echocardiographic assessment to prevent a time delay to and improve the results of revascularization.

\footnotetext{
Abbreviations

CABG: Coronary artery bypass graft; COPD: Chronic obstructive pulmonary disease; CTO: Chronic total occlusion; ECG: Electrocardiogram; ESC: European Society of Cardiology; FMC: First medical contact; IRA: Infarct-related artery; LAD: Left anterior descending artery; LCx: Left circumflex artery; MI: Myocardial infarction; NSTEMI ${ }_{\text {NTO }}$ : Non-ST-segment elevation myocardial infarction without occluded infarct-related artery; NSTEMI cardial infarction with occluded infarct-related artery; ORPKI: Polish National Database of Invasive Coronary Procedures; PCI: Percutaneous coronary intervention; RCA: Right coronary artery; STE: ST-segment elevation; STEMI ST-segment elevation myocardial infarction with occluded infarct-related artery; TIMI: Thrombolysis in myocardial infarction; TO: Total occlusion.
}

\section{Acknowledgements}

Not applicable.

\section{Authors' contributions}

MT, WW and MR designed the study. All authors wrote the main manuscript text. MT, DD, ZS, SB, WW2, MG and MR performed the coronary angiography procedures later included in the ORPKI database. MT, WW and KP performed statistical analyses. MT, WW, TD and JP prepared figures. All authors read and approved the final manuscript.

\section{Funding}

We received no funding for the study.

\section{Availability of data and materials}

The datasets used and/or analysed during the current study are publicly available from the Jagiellonian University Medical College and the Association of Cardiovascular Interventions of the Polish Cardiac Society.

\section{Declarations}

\section{Ethics approval and consent to participate}

Our study was an observational retrospective analysis of anonymized electronic data from the Polish National Database of Invasive Coronary Procedures, which is available to members of the Association of Cardiovascular Interventions of the Polish Cardiac Society. Therefore, in this study, only anonymized data were included in the research analysis, and according to Regulation 2016/679 of the European Parliament and of the Council (EU) from 27 April 2016 on the protection of individuals with regard to the processing of personal data and on the free movement of such data and with art. 9 section 2, this study did not require any additional ethics board approval.

\section{Consent for publication}

Not applicable.

\section{Competing interests}

The authors declare that they have no conflicts of interest.

\section{Author details}

${ }^{1}$ Jagiellonian University Medical College, 1st Department of Cardiology, Interventional Electrocardiology and Arterial Hypertension, Jakubowskiego St. 2, 30-688 Kraków, Poland. ${ }^{2}$ Jagiellonian University Medical College, 2nd Department of Cardiology, Kraków, Poland. ${ }^{3}$ Faculty of Medicine and Health Sciences, Jan Kochanowski University, Kielce, Poland. ${ }^{4}$ KCRI, Kraków, Poland. ${ }^{5}$ Jagiellonian University Medical College, Department of Internal and Agricultural Medicine, Kraków, Poland. ${ }^{6}$ Department of Cardiology and Structura Heart Diseases, Medical University of Silesia, Katowice, Poland. ${ }^{7} 1$ St Department of Cardiology, Poznan University of Medical Sciences, Poznan, Poland.

Received: 2 December 2020 Accepted: 31 May 2021

Published online: 14 June 2021

\section{References}

1. Neumann FJ, Sousa-Uva M, Ahlsson A, et al. 2018 ESC/EACTS guidelines on myocardial revascularization. Eur Heart J. 2019;40:87-165.

2. Schmitt C, Lehmann G, Schmieder S, et al. Diagnosis of acute myocardial infarction in angiographically documented occluded infarct vessel: limitations of ST-segment elevation in standard and extended ECG leads. Chest. 2001;120:1540-6.

3. GUSTO Angiographic Investigators. The effects of tissue plasminogen activator, streptokinase, or both on coronary-artery patency, ventricular function, and survival after acute myocardial infarction. N Engl J Med. 1993;329:1615-22.

4. Dudek D, Siudak Z, Grygier M, et al. Interventional cardiology procedures in Poland in 2018. Summary report of the Association of Cardiovascular Interventions of the Polish Cardiac Society (AISN PTK) and Jagiellonian University Medical College. Adv Interv Cardiol. 2019;15:391-3.

5. Chesebro JH, Knatterud G, Roberts R, et al. Thrombolysis in Myocardial Infarction (TIMI) Trial, Phase I: a comparison between intravenous tissue plasminogen activator and intravenous streptokinase. Clin Find Through Hosp Disch Circ. 1987;76:142.

6. Khan AR, Golwala H, Tripathi A, et al. Impact of total occlusion of culprit artery in acute non-ST elevation myocardial infarction: a systematic review and meta-analysis. Eur Heart J. 2017;38:3082-9.

7. Hung CS, Chen YH, Huang CC, et al. Prevalence and outcome of patients with non-ST segment elevation myocardial infarction with occluded "culprit" artery—a systemic review and meta-analysis. Crit Care. 2018;22:34.

8. Montalescot G, Dallongeville J, Van Belle E, et al. STEMI and NSTEMI: are they so different? 1 year outcomes in acute myocardial infarction as defined by the ESC/ACC definition (the OPERA registry). Eur Heart J. 2007;28:1409-17.

9. Davies MJ, Richardson PD, Woolf $\mathrm{N}$, et al. Risk of thrombosis in human atherosclerotic plaques: role of extracellular lipid, macrophage, and smooth muscle cell content. Br Heart J. 1993;69:377-81.

10. Davies MJ. Acute coronary thrombosis-the role of plaque disruption and its initiation and prevention. Eur Heart J. 1995;16(Suppl L):3-7. 
11. Menon V, Ruzyllo W, Carvalho AC, et al. Infarct artery distribution and clinical outcomes in occluded artery trial subjects presenting with nonST-segment elevation myocardial infarction (from the long-term followup of Occluded Artery Trial [OAT]). Am J Cardiol. 2013;111:930-5.

12. Roleder T, Smolka G, Pysz P, et al. Non-ST elevation myocardial infarction related to total coronary artery occlusion - prevalence and patient characteristics. Postepy Kardiol Interwencyjnej. 2015;11:9-13.

13. Abbott JD, Ahmed HN, Vlachos HA, et al. Comparison of outcome in patients with ST-elevation versus non-ST-elevation acute myocardial infarction treated with percutaneous coronary intervention (from the National Heart, Lung, and Blood Institute Dynamic Registry). Am J Cardiol. 2007;100:190-5.

14. Steg PG, Goldberg RJ, Gore JM, et al. Baseline characteristics, management practices, and in-hospital outcomes of patients hospitalized with acute coronary syndromes in the Global Registry of Acute Coronary Events (GRACE). Am J Cardiol. 2002:90:358-63.

15. Pride YB, Tung P, Mohanavelu S, et al. Angiographic and clinical outcomes among patients with acute coronary syndromes presenting with isolated anterior ST-segment depression: a TRITON-TIMI 38 (Trial to Assess Improvement in Therapeutic Outcomes by Optimizing Platelet Inhibition With Prasugrel-Thrombolysis In Myocardial Infarction 38) substudy. JACC Cardiovasc Interv. 2010;3:806-11.

16. Shin Dl, Chang K, Ahn Y, et al. Impact of occluded culprit arteries on long-term clinical outcome in patients with non-ST-elevation myocardial infarction: 48-month follow-up results in the COREA-AMI Registry. J Interv Cardiol. 2014;27:12-20.

17. Terkelsen CJ, Sørensen JT, Maeng M, et al. System delay and mortality among patients with STEMI treated with primary percutaneous coronary intervention. JAMA. 2010;304:763-71.
18. Grines CL, Cox DA, Stone GW, et al. Coronary angioplasty with or without stent implantation for acute myocardial infarction. Stent Primary Angioplasty in Myocardial Infarction Study Group. N Engl J Med. 1999;341:1949-56.

19. Krishnaswamy A, Lincoff AM, Menon V. Magnitude and consequences of missing the acute infarct-related circumflex artery. Am Heart J. 2009;158:706-12.

20. Stribling WK, Abbate A, Kontos M, et al. Myocardial infarctions involving acute left circumflex occlusion: are all occlusions created equally? Interv Cardiol. 2010;2:695-704

21. Hochman JS, Lamas GA, Buller CE, et al. Coronary intervention for persistent occlusion after myocardial infarction. N Engl J Med. 2006:355:2395-407.

22. Collet J-P, Thiele H, Barbato E, et al. ESC Scientific Document Group, 2020 ESC Guidelines for the management of acute coronary syndromes in patients presenting without persistent ST-segment elevation: The Task Force for the management of acute coronary syndromes in patients presenting without persistent ST-segment elevation of the European Society of Cardiology (ESC). Eur Heart J. 2021;42:1289-367.

\section{Publisher's Note}

Springer Nature remains neutral with regard to jurisdictional claims in published maps and institutional affiliations.
Ready to submit your research? Choose BMC and benefit from:

- fast, convenient online submission

- thorough peer review by experienced researchers in your field

- rapid publication on acceptance

- support for research data, including large and complex data types

- gold Open Access which fosters wider collaboration and increased citations

- maximum visibility for your research: over $100 \mathrm{M}$ website views per year

At $\mathrm{BMC}$, research is always in progress.

Learn more biomedcentral.com/submissions 